\title{
Intravenous Methylene Blue as a Rescue Therapy in the Management of Refractory Hypoxia in COVID-19 ARDS Patients: A Case Series
}

Nilesh Mahale ${ }^{1} \odot$, Purushotham Godavarthy ${ }^{2} \odot$, Srinath Marreddy ${ }^{3} \odot$, Snehal D Gokhale ${ }^{4} \odot$, Pradip Funde ${ }^{5} \oplus$, Prasad A Rajhans $^{6} \odot$, Prasad V Akole ${ }^{7} \odot$, Balasaheb Pawar ${ }^{8} \odot$, Bhagyashri Bhurke ${ }^{9} \odot$, Pradip Dalvi ${ }^{10} \odot$, Prasanna Marudwar ${ }^{11} \odot$, Shradha Gugale ${ }^{12} \odot$, Manasi S Shahane ${ }^{13} \odot$, Sarang N Kshirsagar ${ }^{14} \odot$, Sameer A Jog ${ }^{15} \odot$

\begin{abstract}
Objectives: To describe the clinical outcomes of hypoxic coronavirus disease 2019 (COVID-19) patients treated with intravenous methylene blue (MB) in a tertiary care hospital.

Materials and methods: We conducted a case series of 50 patients with hypoxic COVID-19 treated with intravenous MB admitted to our hospital between June 01 and September 10, 2020. Intravenous MB was administered as rescue therapy in dosage of $1 \mathrm{mg} / \mathrm{kg}$ body weight, with a maximum of five doses, to patients with high oxygen requirements $\left(\mathrm{SpO}_{2} / \mathrm{FiO}_{2}<200\right)$ apart from the standard of care after obtaining G6PD levels. Data were abstracted from multiple electronic data sources or patient charts to provide information on patient characteristics, clinical and laboratory variables and outcomes.

Results: The median age of the patients was 53.3 (range 25-74 years) and most patients (74\%) were men. About 68\% of patients had pre-existing comorbidity. Median $\mathrm{SpO}_{2} / \mathrm{FiO}_{2}$ ratio progressively improved from 132.5 (predose) to 284 before the terminal event (death or discharge), ventilator-free days, and decrease in the proinflammatory biochemical parameter was significantly higher after the second dose of MB. A total of six patients out of 50 required invasive mechanical ventilation (IMV). Thirty patients were discharged with a recovery rate of $60 \%$, while 20 patients succumbed to the illness. There was no major side effect or adverse event reported in any of the patients.

Conclusion: MB due to its polypharmacological action against SARS-CoV-2, an inexpensive and widely available drug with minimal side effects, has a significant potential in the treatment of COVID-19.

Keywords: Acute respiratory distress syndrome, Coronavirus disease 2019, Methylene blue, Rescue therapy.

Indian Journal of Critical Care Medicine (2021): 10.5005/jp-journals-10071-23905
\end{abstract}

\section{INTRODUCTION}

Coronavirus disease 2019 (COVID-19) caused by the severe acute respiratory syndrome-coronavirus 2 (SARS-CoV-2) has severely impacted healthcare systems all over the world. Though the exact pathogenesis of SARS-CoV-2 is unknown, various hypotheses have proposed cytokine storm or hyperinflammatory syndrome as probable causes for the rapid worsening of the disease. ${ }^{1-3}$ Various drugs have been repurposed for treatment in the absence of definitive therapy with emphasis on the provision of supportive care including oxygenation, ventilator support, and other critical care life supports. ${ }^{4}$

The first COVID positive patient admitted at our hospital was on March 22, 2020, and to date, around 1,200 moderately to severe hypoxic COVID patients have been managed at our ICU. In view of resource-limited setting, rationing of available medical resources and constant modification of treating protocols keeping the patient safety were done to keep up with the pace of increased patient load.

Methylene blue (MB) or Bis (dimethylamino) phenazathionium chloride trihydrate, an organic dye, has been used extensively in an array of clinical conditions for the past two centuries. Few clinical conditions where the role of MB has been documented include treatment of malaria, refractory septic shock, catecholamine refractory vasoplegia, methemoglobinemia, and therapeutic benefit in hypoxia caused due to pulmonary vasodilation in patients
${ }^{1-15}$ Department of Critical Care Medicine, Deenanath Mangeshkar Hospital and Research Center, Pune, Maharashtra, India

Corresponding Author: Nilesh Mahale, Department of Critical Care Medicine, Deenanath Mangeshkar Hospital and Research Center, Pune, Maharashtra, India, Phone: +919082919254, e-mail: nilesh.mahale0@ gmail.com

How to cite this article: Mahale N, Godavarthy $P$, Marreddy $S$, Gokhale SD, Funde P, Rajhans PA, et al. Intravenous Methylene Blue as a Rescue Therapy in the Management of Refractory Hypoxia in COVID-19 ARDS Patients: A Case Series. Indian J Crit Care Med 2021;25(8):934-938.

Source of support: Nil

Conflict of interest: None

of hepatopulmonary syndrome due to inhibition of guanylate cyclase and nitric oxide synthetase..$^{5-9}$

Various theories have been postulated highlighting the benefits of administering MB as a salvage therapy among COVID-19 patients for its antiviral, anti-inflammatory, and antioxidant properties and have been proposed as a rescue therapy for improving the refractory hypoxia in COVID-19 patients. ${ }^{10,11}$ Till date, no clinical trials have been conducted evaluating the clinical effects of MB among COVID-19 patients.

(0) Jaypee Brothers Medical Publishers. 2021 Open Access This article is distributed under the terms of the Creative Commons Attribution 4.0 International License (https://creativecommons.org/licenses/by-nc/4.0/), which permits unrestricted use, distribution, and non-commercial reproduction in any medium, provided you give appropriate credit to the original author(s) and the source, provide a link to the Creative Commons license, and indicate if changes were made. The Creative Commons Public Domain Dedication waiver (http://creativecommons.org/publicdomain/zero/1.0/) applies to the data made available in this article, unless otherwise stated. 
Henry et al. ${ }^{12}$ proposed that MB could be of considerable help in the management of COVID-19 based on a survey of 2,500 French patients, treated with a combination of $\alpha$-lipoic acid, hydroxycitrate, and MB as part of cancer care, in whom nil infections of the virus were reported. Also, MB in presence of light has broad-spectrum virucidal activity and has been used to inactivate viruses in blood products prior to transfusions. ${ }^{13}$ Recently, Cagno et al. ${ }^{14}$ documented in vitro antiviral properties of $\mathrm{MB}$ at low micromolar concentrations when incubated with Vero E6 cells and SARS-CoV-2 for 20 hours in the dark. Damir Bojadzic et al. ${ }^{15}$ proposed that $\mathrm{MB}$ inhibits the viral attachment and entry of SARS-CoV-2 by blocking the protein-protein interaction (PPI) of its spike protein with ACE2 on the host cell which is the first critical step initiating the viral entry. They suggested that this antiviral activity could be useful in the prevention and treatment of COVID-19 either as an oral or inhaled medication.

A phase one clinical trial documented a positive response in four out of five severely ill COVID-19 patients who were administered $\mathrm{MB}$ as a part of a three-drug regimen comprising of $M B$, vitamin $C$, and $\mathrm{N}$-acetyl cysteine. ${ }^{16}$

In this study, we present a case series of 50 moderate to severe hypoxic COVID-19 patients who were administered intravenous $M B$ as a rescue therapy at the discretion of the treating physician in addition to the standard of care treatment. Apart from the proposed above-mentioned clinical benefits, excellent safety profile, easy availability, low cost and minimal interactions with other drugs were factors considered for treatment with MB.

\section{Materials and Methods}

\section{Study Overview}

The study was conducted by the Department of Critical Care Medicine in a tertiary care hospital located in Pune, India. The study was approved by the Institutional Ethics Committee and owing to the retrospective nature of the study, and waiver of informed consent was obtained.

\section{Criteria for Patient Selection}

Based on the clinical information available about MB at that time, the treating physicians preagreed upon the following inclusion and exclusion criteria.

\section{Inclusion Criteria}

- Confirmed case of COVID-19 (by RT-PCR, antigen)

- Admission to intensive care unit

- $\mathrm{PaO}_{2} / \mathrm{FiO}_{2}<200$ or $\mathrm{SpO}_{2} / \mathrm{FiO}_{2}<200$

\section{Exclusion Criteria}

- Pregnancy and breastfeeding

- History of G6PDH deficiency

- Severe renal insufficiency (glomerular filtration rate $<30 \mathrm{~mL}$ / minute $/ 1.73 \mathrm{~m}^{2}$ )

- Severe hepatic disease defined by SGOT or SGPT levels three times above the normal upper limit

- Patients with a history of allergic reaction or significant sensitivity to $M B$

Owing to the huge deluge of patients and with limited resources, $\mathrm{PaO}_{2} / \mathrm{FiO}_{2}$ ratio of all patients could not be calculated and
$\mathrm{SpO}_{2} / \mathrm{FiO}_{2}$ ratio was used as a substitute to monitor the patients. $\mathrm{SpO}_{2} / \mathrm{FiO}_{2}$ ratio has been validated in various clinical settings as an alternate to $\mathrm{PaO}_{2} / \mathrm{FiO}_{2}$ ratio. ${ }^{17-19}$

Standard of care, such as antivirals, steroids, and anticoagulants, was administered apart from oxygen supplementation by nasal cannula, nonrebreather mask (NRBM), high flow nasal cannula (HFNC), or noninvasive ventilation (NIV) as per the hospital protocol and discretion of the treating physician. Invasive mechanical ventilation was initiated based on the clinical assessment and $\mathrm{SpO}_{2} / \mathrm{FiO}_{2}$ of the patients.

Intravenous MB was administered as rescue therapy in dosage of $1 \mathrm{mg} / \mathrm{kg}$ body weight to critically III patients admitted to ICU with high oxygen requirements $\left(\mathrm{SpO}_{2} / \mathrm{FiO}_{2}<200\right)$ and those who met the inclusion criteria apart from the standard of care after obtaining G6PD levels. A maximum of five doses of MB was given as per the clinical improvement, side effects, and discretion of treating physicians.

\section{Data Source}

Data were collected between June 01 and September 10, 2020, and the clinical outcomes were monitored till October 30, 2020. Demographics, clinical, and laboratory data on admission and the subsequent trends, mode of respiratory support (invasive mechanical ventilation, noninvasive mechanical ventilation, and oxygen mask), fraction of inspired oxygen $\left(\mathrm{FiO}_{2}\right)$, $\mathrm{SpO}_{2} / \mathrm{FiO}_{2}$ ratio and treatment administered were collected from the electronic medical records. The collected data were analyzed and interpreted by two independent intensivists. The clinical team provided clarification on missing or redundant data.

\section{Data Analysis}

Data were analyzed using descriptive statistics. Pair-wise statistical comparisons of normally distributed continuous variables were done using repeated measures analysis of variance or non-normally distributed continuous variables the Pair-wise statistical comparisons were done using Wilcoxon's signed-rank test. The underlying normality assumption was tested before subjecting study variables to RMANOVA. In the entire study, the $p$-values less than 0.05 were considered to be statistically significant. The entire data were statistically analyzed using Statistical Package for Social Sciences (SPSS ver 22.0, IBM Corporation, USA) for MS Windows.

\section{Study Outcomes \\ Results}

A total of 50 patients were included in the study. The age of the patients ranged from 25 to 74 years (mean $53.3 \pm 12.2$ years; Table 1). The majority of patients were male (74\%). Pre-existing comorbidities were reported in $68 \%$ of patients with diabetes (14\%), hypertension (16\%), 30\% of patients reported having both diabetes and hypertension, and $8 \%$ of patients other comorbidities.

Patients with $\mathrm{SpO}_{2} / \mathrm{FiO}_{2}<200$ were included in the study, the lowest ratio was 84 and the highest was 196 (mean 132.5, SD 33.3). Eighty-two percentage patients were on HFNC, $8 \%$ on NRBM, 10\% on NIV prior to starting of MB (Table 4).

Distribution of Mean $\mathrm{SpO}_{2} / \mathrm{FiO}_{2}$ Ratio Prior and Post-MB Administration. 
Median $\mathrm{SpO}_{2} / \mathrm{FiO}_{2}$ ratio improved from 132.5 (predose) to 189.3 after administration of third or higher doses of MB with a mean ratio of 284 documented before the terminal event (death or discharge). The distribution of the mean $\mathrm{SpO}_{2} / \mathrm{FiO}_{2}$ ratio post-MB administration was significantly higher compared to mean $\mathrm{SpO}_{2} / \mathrm{FiO}_{2}$ ratio prior to $\mathrm{MB}$ administration ( $p$-value $<0.001$ ) (Figs 1 and 2, Tables 2,3,5).

- Dose 1 of MB: Mean duration of ventilator-free days did not differ significantly between the two group of cases with $\mathrm{SpO}_{2} / \mathrm{FiO}_{2}$ less than or more than $200(p>0.05)$.

- Dose 2 of MB: Mean duration of ventilator-free days was significantly higher in group of cases with $\mathrm{SpO}_{2} / \mathrm{FiO}_{2}>200$, compared to cases with $\mathrm{SpO}_{2} / \mathrm{FiO}_{2}<200(p<0.05)$.

- Dose 3 of MB: Mean duration of ventilator-free days did not differ significantly between the two group of cases with $\mathrm{SpO}_{2} / \mathrm{FiO}_{2}$ less than or more than 200 ( $p$-value $>0.05$ ).

- Before terminal event: Mean duration of ventilator-free days was significantly higher in group of cases with $\mathrm{SpO}_{2} / \mathrm{FiO}_{2}$ more than 200 compared to group of cases with $\mathrm{SpO}_{2} / \mathrm{FiO}_{2}$ less than 200 ( $p$-value $<0.05$ ).

Six out of 50 patients required Invasive mechanical ventilation during the period of study.

A significant decrease in the proinflammatory biochemical parameter (CRP) was noticed post-MB administration.

No significant improvement in absolute lymphocyte count (ALC) was observed post-MB administration.

Table 1: Distribution of demographic characteristics of cases studied

\begin{tabular}{llll}
\hline & & No. of cases & \% of cases \\
\hline $\begin{array}{l}\text { Age group } \\
\text { (years) }\end{array}$ & $<40$ & 7 & 14.0 \\
& $40-49$ & 11 & 22.0 \\
& $50-59$ & 15 & 30.0 \\
& $60-69$ & 10 & 20.0 \\
& $>70$ & 7 & 14.0 \\
Sex & Mean \pm SD & $53.3 \pm 12.2$ & \\
& Male & 37 & 74.0 \\
Comorbidity & Female & 13 & 26.0 \\
& Absent & 16 & 32.0 \\
& Diabetes mellitus & 7 & 14.0 \\
& Hypertension & 8 & 16.0 \\
& Diabetes mellitus & 15 & 30.0 \\
& + hypertension & & \\
& Other & 4 & 8.0 \\
\hline
\end{tabular}

Thirty patients were discharged with a recovery rate of 60 . The average total length of stay during hospitalization was $14.24 \pm 4.15$ days.

No patient was lost to follow up and there were no major side effects or adverse events reported in any of the 50 patients, except for temporary bluish discoloration of urine.

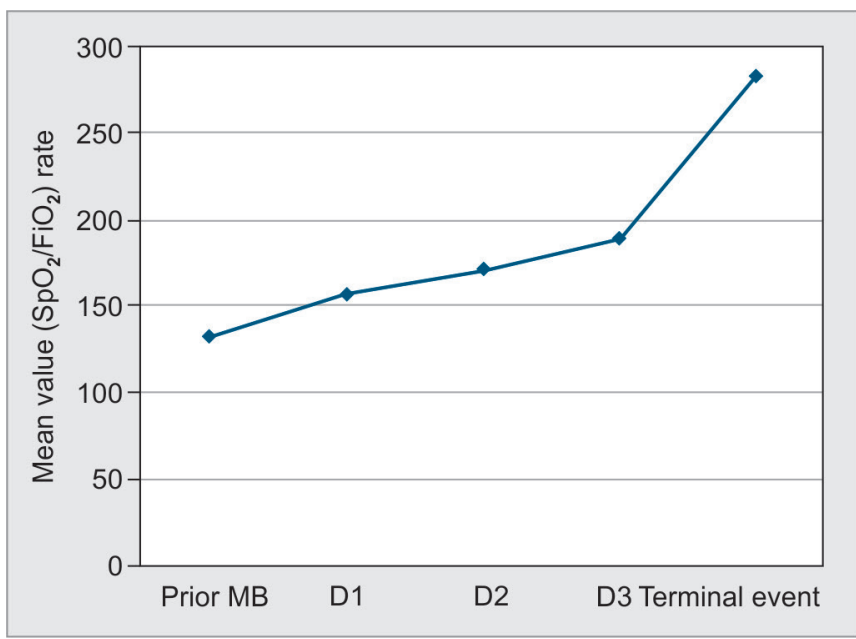

Fig. 1: Distribution of mean $\mathrm{SpO}_{2} / \mathrm{FiO}_{2}$ ratio prior and post-MB administration

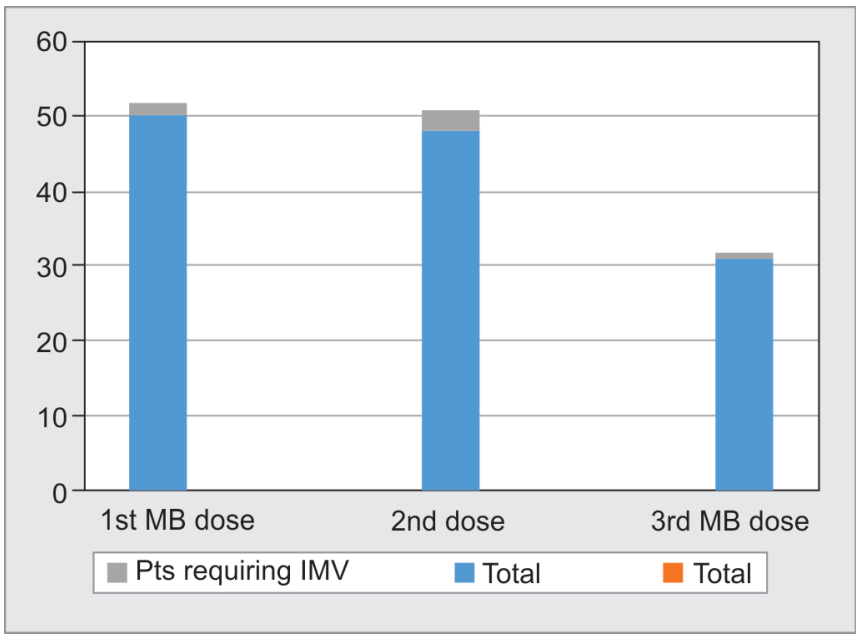

Fig. 2: Distribution of requirement of IMV vs dosage of MB

Table 2: Distribution of mean $\mathrm{SpO}_{2} / \mathrm{FiO}_{2}$ ratio prior and post-MB administration

\begin{tabular}{lcccccc}
\hline $\mathrm{SpO}_{2} / \mathrm{FiO}_{2}$ ratio & $\begin{array}{l}\text { Prior to first } \\
\text { dose of } \mathrm{MB}\end{array}$ & $\begin{array}{l}\text { Post-first } \\
\text { dose }\end{array}$ & $\begin{array}{l}\text { Post-second } \\
\text { dose }\end{array}$ & $\begin{array}{l}\text { Post-third } \\
\text { dose }\end{array}$ & $\begin{array}{l}\text { Before the terminal event } \\
\text { (death or discharge) }\end{array}$ & $p$ value \\
\hline$n$ & 50 & 50 & 49 & 31 & 50 & $0.001^{* * *}$ \\
Mean & 132.5 & 156.9 & 171.4 & 189.3 & 284.1 & 159.0 \\
$\mathrm{SD}$ & 33.3 & 47.9 & 53.9 & 63.1 & 15.0 & \\
\hline
\end{tabular}

$p$ value by repeated measures ANOVA (RMANOVA); $p$-value $<0.05$ is considered to be statistically significant.

${ }^{* * *} p$-value $<0.001$ 
Table 3: Distribution of mean $\mathrm{SpO}_{2} / \mathrm{FiO}_{2}$ ratio vs ventilator-free days

\begin{tabular}{|c|c|c|c|c|c|}
\hline \multirow{2}{*}{ Characteristics } & & \multicolumn{3}{|c|}{ Ventilator-free days } & \multirow[b]{2}{*}{$p$ value } \\
\hline & & $n$ & Mean & $S D$ & \\
\hline \multirow{2}{*}{$\begin{array}{l}\left.\mathrm{SpO}_{2} / \mathrm{FiO}_{2} \text { (After dose } 1\right) \\
n=50\end{array}$} & $<200$ & 42 & 24.2 & 6.2 & \multirow[t]{2}{*}{$0.353^{\mathrm{NS}}$} \\
\hline & $>200$ & 8 & 26.0 & 2.7 & \\
\hline \multirow{2}{*}{$\begin{array}{l}\mathrm{SpO}_{2} / \mathrm{FiO}_{2}(\text { After dose } 2) \\
n=50\end{array}$} & $<200$ & 36 & 23.4 & 6.6 & \multirow[t]{2}{*}{$0.041^{*}$} \\
\hline & $>200$ & 14 & 26.8 & 2.3 & \\
\hline \multirow{2}{*}{$\begin{array}{l}\mathrm{SpO}_{2} / \mathrm{FiO}_{2} \text { (After dose } 3 \text { ) } \\
n=31\end{array}$} & $<200$ & 17 & 22.9 & 7.6 & \multirow[t]{2}{*}{$0.265^{\mathrm{NS}}$} \\
\hline & $>200$ & 14 & 25.6 & 5.6 & \\
\hline \multirow{2}{*}{$\begin{array}{l}\mathrm{SpO}_{2} / \mathrm{FiO}_{2} \text { (terminal } \\
\text { event) }\end{array}$} & $<200$ & 20 & 22.0 & 4.8 & \multirow[t]{2}{*}{$0.007^{* *}$} \\
\hline & $>200$ & 30 & 26.2 & 5.7 & \\
\hline
\end{tabular}

$p$ value by Wilcoxon's signed-rank test; $p$-value $<0.05$ is considered to be statistically significant, ${ }^{* * *} p$-value $<0.001 ; N S$, statistically non significant

Table 4: Requirement of invasive mechanical ventilation among patients given MB

\begin{tabular}{lclll}
\hline & Prior to $M B$ & After dose 1 & After dose 2 & After dose 3 \\
\hline HFNO & 41 & 43 & 39 & 25 \\
NIV & 5 & 3 & 2 & 3 \\
NRBM & 4 & 2 & 6 & 2 \\
IMV & 0 & 2 & 3 & 1 \\
IMV ratio & & $2 / 50$ & $3 / 48$ & $1 / 31$ \\
IMV (\%) & & 4 & 6.25 & 3.22 \\
\hline
\end{tabular}

Table 5: Distribution of median CRP and ALC prior and post-MB administration

\begin{tabular}{lllll}
\hline Parameter & & Prior to MB & Post-MB & p value \\
\hline CRP & Median & 106.6 & 22.7 & $0.001^{* * *}$ \\
& Min-max & $13.69-325.70$ & $2.80-275.77$ & \\
ALC & Median & 820.0 & 880.0 & $0.079^{\mathrm{NS}}$ \\
& Min-max & $80-1,850$ & $80-4,220$ & \\
\hline
\end{tabular}

$p$ value by Wilcoxon's signed-rank test; $p$-value $<0.05$ is considered to be statistically significant; ${ }^{* * *} p$-value $<0.001$; NS, statistically non-significant

\section{Discussion}

This case series would be to our knowledge the first study in India that presents data of hypoxic COVID-19 patients treated with intravenous MB. During the review of the literature, we could not find any data or clinical trials pertaining to the administration of intravenous MB for the treatment of COVID-19 patients.

The rapid surge in the number of patients infected with COVID and the high caseload on the hospitals have led medical researchers to identify new drugs that could help treat patients with COVID- 19. Various drugs with known safety profiles, easy availability, and effectiveness in managing complications have been studied. MB an organic dye has been used extensively in an array of clinical conditions for the past two centuries and has been proposed as a rescue therapy for improving the refractory hypoxia in COVID-19 patients. Various theories have been postulated highlighting the benefits of administering MB as a salvage therapy among COVID- 19 patients including antiviral, anti-inflammatory, and antioxidant properties. $^{20}$

$\mathrm{MB}$ in presence of light has broad-spectrum virucidal activity and has been used to inactivate viruses in blood products prior to transfusions. ${ }^{13}$ Recently, Cagno et al. ${ }^{14}$ documented in vitro antiviral properties of $\mathrm{MB}$ at low micromolar concentrations when incubated with Vero E6 cells and SARS-CoV-2 for 20 hours in the dark. Bojadzic et al. ${ }^{15}$ proposed that MB inhibits the viral attachment and entry of SARS-CoV-2 by blocking the PPI of its spike protein with ACE2 on the host cell which is the first critical step initiating the viral entry. They suggested that this antiviral activity could be useful in the prevention and treatment of COVID-19 either as an oral or inhaled medication. Gendrot et al. ${ }^{21}$ demonstrated that nonphoto-activated MB showed high in vitro antiviral effective activity against SARSCoV-2 with an inhibitory concentration (IC) IC50 (0.3 $\mu \mathrm{M})$ and IC90 $(0.75 \mu \mathrm{M})$ compatible with oral uptake and IV administration. This in vitro activity was higher than those obtained with drugs such as hydroxychloroquine $(1.5 \mu \mathrm{M})$, azithromycin $(20.1 \mu \mathrm{M})$, remdesivir $(23 \mu \mathrm{M})$, lopinavir $(26.6 \mu \mathrm{M})$, or ritonavir $(>100 \mu \mathrm{M})$. Barber et al. and Vardhana et al. reported that MB by blocking the downstream cosignaling PPIs of the cytotoxic T lymphocytes, restores their cytotoxicity, activation, proliferation, and cytokine secreting activity thereby restoring $T$ cell homeostasis and function, which in turn improves viral clearance. 22,23

Henry et al. ${ }^{12}$ proposed that MB could be of considerable help in the management of COVID-19 based on a survey of 2,500 French patients treated with a combination of a-lipoic acid, hydroxycitrate, and $M B$ as part of cancer care in whom nil infections of the virus were reported. They proposed that upon absorption, $\mathrm{MB}$ undergoes one-electron reduction and becomes a neutral lipophilic MB radical. This radical acts as a weak base ( $\mathrm{pKa} \sim 9$ ) which could cause transient alkalization of cytosolic spaces. As acidic media $(\mathrm{PH}<5)$ is mandatory for endosome maturation and function, this alkalization could inhibit endosome maturation at intermediate stages of endocytosis resulting in failure of further import of virions into the cytosol. These antiviral properties of MB could be used as a treatment in COVID patients. Ghahestani et al. ${ }^{10}$ described the pivotal role of the Kininogen system in the pathogenesis of SARS-CoV-2 and suggested the hypothetical potential of MB being an inhibitor of NO synthetase could abort effects of bradykinin and could be used in the treatment of SARS-CoV-2 to improve oxygen saturation.

$M B$ is generally safe, but dose-dependent toxicity with nausea, vomiting, hemolysis, and other undesired side effects at doses $>7 \mathrm{mg} / \mathrm{kg}$ (i.e., $>500 \mathrm{mg}$ ) is known. 6,7

At our center, intravenous MB was administered as per the discretion of the treating physician in patients who had $\mathrm{SpO}_{2} / \mathrm{FiO}_{2}$ ratio $<200$ and was refractory to the best of supportive care being provided. Dosage was restricted to a maximum of $5 \mathrm{mg} / \mathrm{kg}$ of intravenous MB in a divided dose. No major adverse events were documented in any of the fifty patients who were administered intravenous $\mathrm{MB}$ except for temporary bluish discoloration of urine.

There was a significant improvement in the $\mathrm{SpO}_{2} / \mathrm{FiO}_{2}$ ratios progressively after the second dose of IV $\mathrm{MB}$ and it was statistically significant at the terminal event (death or discharge). The distribution of mean $\mathrm{SpO}_{2} / \mathrm{FiO}_{2}$ ratio post-MB administration was higher compared to the ratio prior to MB administration. We also noted that the mean duration of ventilator-free days was significantly higher in group with $\mathrm{SpO}_{2} / \mathrm{FiO}_{2}>200$ compared to the group with $\mathrm{SpO}_{2} / \mathrm{FiO}_{2}<200$ before the terminal event. Progression from noninvasive to IMV was seen in 6 patients out of 50. A significant reduction in the proinflammatory biochemical parameter (CRP) was noticed post-MB dosage.

\section{Limitations}

We acknowledge the limitations of our study. First, this was a case series carried out in a single center with all its inherited biases. Second, the data were collected from electronic medical health 
record database, thereby precluding detailed information about the patient's demographics and baseline medications. Third, the nonuniformity in the selection of the study subjects due to the participants' inclusion criteria as well as by the studies design, limited investigations were conducted due to cost constraints, high heterogeneity observed in the number of doses as well as the timing of administration of the drug making the data redundant for comparative analysis.

\section{Implications for Future Research}

Larger trials with a more robust study design, randomized control trials comparing IV MB with a standard of care in regards to important clinical outcome variables.

\section{Conclusion}

MB due to its polypharmacology in the action against SARS-CoV-2, being an inexpensive and widely available drug potentially has a significant role in the treatment of COVID-19.

\section{ORCID}

Nilesh Mahale ㄴ) https://orcid.org/0000-0002-7952-8259 Purushotham Godavarthy $\odot$ https://orcid.org/0000-0002-5727-3419 Srinath Marreddy (1) https://orcid.org/0000-0002-8405-7500 Snehal D Gokhale (1) https://orcid.org/0000-0002-0183-2023 Pradip Funde ำ https://orcid.org/0000-0003-0790-9949 Prasad A Rajhans (ㄴ) https://orcid.org/0000-0002-0111-6123 Prasad V Akole 이 https://orcid.org/0000-0001-5655-7471 Balasaheb Pawar (1) https://orcid.org/0000-0001-9622-8357 Bhagyashri Bhurke ㄴ https://orcid.org/0000-0002-5139-7955 Pradip Dalvi @ https://orcid.org/0000-0002-7690-5426 Prasanna Marudwar (1) https://orcid.org/0000-0002-2730-8641 Shradha Gugale ㄴ https://orcid.org/0000-0003-1476-248X Manasi S Shahane 이 https://orcid.org/0000-0002-5304-9647 Sarang N Kshirsagar @ https://orcid.org/0000-0002-5541-2905 Sameer A Jog @ i https://orcid.org/0000-0002-1134-1260

\section{References}

1. van de Veerdonk F, Netea MG, van Deuren M, van der Meer JW, de Mast Q, Bruggemann RJ, et al. Kinins and cytokines in COVID-19: a comprehensive pathophysiological approach. Preprints 2020. DOI: 10.20944/preprints202004.0023.v1.

2. Moore JB, June $\mathrm{CH}$. Cytokine release syndrome in severe COVID-19. Science 2020;368(6490):473-474. DOI: 10.1126/science. abb8925.

3. Ye $Q$, Wang $B$, Mao J. The pathogenesis and treatment of the 'cytokine storm' in COVID-19. J Infect 2020;80(6):607-613. DOI: 10.1016/j.jinf. 2020.03.037.

4. Salvi R, Patankar P. Emerging pharmacotherapies for COVID-19. Biomed Pharmacother 2020;128:110267. DOI: 10.1016/ j. biopha.2020.110267.

5. Kwok ES, Howes D. Use of methylene blue in sepsis: a systematic review. J Intensive Care Med 2006;21(6):359-363. DOI: $10.1177 / 0885066606290671$.

6. Bistas E, Sanghavi D. Methylene Blue. [Updated 2020 Jul 2]. In: StatPearls [Internet]. Treasure Island (FL): StatPearls Publishing; 2021 Jan-. Available from: https://www.ncbi.nlm.nih.gov/books/ NBK557593/
7. Clifton J II, Leikin JB. Methylene blue. Am J Therapeut 2003;10(4): 289-291. DOI: 10.1097/00045391-200307000-00009.

8. Schenk P, Madl C, Rezaie-Majd S, Lehr S, Müller C. Methylene blue improves the hepatopulmonary syndrome. Ann Intern Med 2000;133(9):701-706. DOI: 10.7326/0003-4819-133-9-200011070-00012.

9. Mayer B, Brunner F, Schmidt K. Inhibition of nitric oxide synthesis by methylene blue. Biochem Pharmacol 1993;45(2):367-374. DOI: 10.1016/0006-2952(93)90072-5.

10. Ghahestani SM, Shahab E, Karimi S, Madani MH. Methylene blue may have a role in the treatment of COVID-19. Med Hypotheses 2020;144:110163. ISSN 0306-9877. DOI: 10.1016/j.mehy.2020.110163.

11. Floyd RA, Schinazi RF. Antiviral therapy using thiazine dyes. Google Patents 2002:6346529. Available from: http://www.freepatentsonline. com/6346529.html.

12. Henry M, Summa M, Patrick L, Schwartz L. A cohort of cancer patients with no reported cases of SARS-CoV-2 infection: the possible preventive role of Methylene Blue. Substantia 2020;4(1):888. DOI: 10.13128/Substantia-888.

13. Yu B, Jin C, Zhang J, Wu H, Zhou X, Yao H, et al. Methylene blue photochemical treatment as a reliable SARS-CoV-2 plasma virus inactivation method for blood safety and convalescent plasma therapy for the COVID-19 outbreak. BMC Infect Dis 2021;21(1):357. DOI: 10.1186/s12879-021-05993-0.

14. Cagno V, Medaglia C, Cerny A, Cerny T, Tapparel C, Cerny E. Methylene blue has a potent antiviral activity against SARSCoV-2 in the absence of UV-activation in vitro. bioRxiv 2020. DOI: 10.1101/2020.08.14.251090.

15. Bojadzic D, Alcazar O, Buchwald P. Methylene Blue inhibits the SARS-CoV-2 Spike-ACE2 Protein-Protein interaction - a mechanism that can contribute to its antiviral activity against COVID-19. Front Pharmacol 2021;11:600372. DOI: 10.3389/fphar.2020.600372.

16. Alamdari DH, Moghaddam AB, Amini S, Keramati MR, Zarmehri AM, Alamdari $\mathrm{AH}$, et al. Application of methylene blue-vitamin C-Nacetyl cysteine for treatment of critically ill COVID-19 patients, report of a phase-I clinical trial. Eur J Pharmacol 2020;885:173494. DOI: 10.1016/j. ejphar.2020.173494.

17. Rice TW, Wheeler AP, Bernard GR, Hayden DL, Schoenfeld DA, Ware LB. Comparison of the $\mathrm{SpO}_{2} / \mathrm{FiO}_{2}$ ratio and the $\mathrm{PaO}_{2} / \mathrm{FiO}_{2}$ ratio in patients with acute lung injury or ARDS. Chest 2007;132(2):410-417. DOI: 10.1378/chest.07-0617.

18. Pisani $L$, Roozeman JP, Simonis $F D$, Giangregorio $A$, van der Hoeven SM, Schouten LR, et al. Risk stratification using $\mathrm{SpO}_{2} / \mathrm{FiO}_{2}$ and PEEP at initial ARDS diagnosis and after $24 \mathrm{~h}$ in patients with moderate or severe ARDS. Ann Intensive Care 2017;7(1):108. DOI: 10.1186/s13613-017-0327-9.

19. Brown SM, Grissom CK, Moss M, Rice TW, Schoenfeld D, Hou PC, et al. $\mathrm{NIH} / \mathrm{NHLBI}$ PETAL Network Collaborators. Nonlinear imputation of $\mathrm{PaO}_{2} / \mathrm{FiO}_{2}$ from $\mathrm{SpO}_{2} / \mathrm{FiO}_{2}$ among patients with acute respiratory distress syndrome. Chest 2016;150(2):307-313. DOI: 10.1016/j. chest.2016.01.003. PMID:26836924.

20. Golwalkar D. Treatment for COVID-19 using methylene blue. Medium. 2020. Available at: https://medium.com/@dr.deepak.golwalkar/ treatment-for-covid-19-using-methylene-blue-d23fc5a31a4d [Accessed April 12, 2020].

21. Gendrot M, Andreani J, Duflot I, Boxberger M, Bideau ML, Mosnier J, et al. Methylene blue inhibits replication of SARS-CoV-2 in vitro. Int J Antimicrob Agents 2020;56:106202. DOI: 10.1016/j. ijantimicag.2020.106202.

22. Barber DL, Wherry EJ, Masopust D, Zhu B, Allison JP, Sharpe AH, et al. Restoring function in exhausted CD8 T cells during chronic viral infection. Nature 2006;439(7077):682-687. DOI: 10.1038/nature04444.

23. Vardhana SA, Wolchok JD. The many faces of the anti-COVID immune response. J Exp Med 2020;217(6):e20200678. DOI: 10.1084/ jem.20200678. 